\title{
Selective attraction of marine bacterivorous nematodes to their bacterial food
}

\author{
Tom Moens ${ }^{1, *}$, Lesley Verbeeck ${ }^{1}$, An de Maeyer $^{1}$, Jean Swings ${ }^{2}$, Magda Vincx ${ }^{1}$ \\ ${ }^{1}$ Department of Biology, Marine Biology Section, and ${ }^{2}$ Laboratory of Microbiology, University of Gent, \\ K. L. Ledeganckstraat 35, B-9000 Gent, Belgium
}

\begin{abstract}
This paper explores the role of selective attraction to food in determining the spatial (micro)distribution of closely related nematode species. The attractiveness of 3 different bacterial strains to 4 species of Monhysteridae, Diplolaimelloides meyli. Diplolaimella dievengatensis, Monhystera sp. and Geomonhystera disjuncta, was studied in a multiple choice design. In our study area, the 4 nematode species considered are associated with Spartina anglica detritus decay and have partially overlapping microhabitat preferences. As they all belong to the same feeding guild, they are potential competitors for food. Each of the 4 nematode species was attracted to the bacterial strain B1, but important interspecific differences were noted in the nematodes' response to live or heat-killed bacteria, to bacteria at different cell densities or of different age, and to the filtered supernatant of B1 culture. While the responses of $D$. meyli to the Gram-positive bacteria Halobacillus trueperi and to the Gramnegative Escherichia coli were similar, D. dievengatensis and Monhystera sp. were preferentially attracted to $H$. trueperi and $E$. coli, respectively. This opposite preference influenced both the numbers and their relative abundances of $D$. dievengatensis and Monhystera sp. inside bacterial patches in experiments with a mixed 2 -species nematode inoculum. Bacterial cell density strongly influenced the nematode response, with $D$. meyli invariably preferring the highest cell densities offered, while $D$. dievengatensis and Monhystera sp. had a peak response at lower cell densities. Though chemotaxis is suggested as an underlying mechanism, the nature of the nematodes' response remains unproved. The present results strongly support the importance of food patchiness in determining the heterogeneous distribution of nematodes, and extend the concept in such a way as to allow for small differences in microhabitat choice between closely related species. They also support the view that nematodes are specialist feeders, though they probably select spots where suitable food is plentiful rather than individual food particles. Finally, the present study offers a baseline for an understanding and further study of patterns of succession among nematode species associated with decaying Spartina anglica detritus in terms of highly specific relationships with different strains, growth stages, and densities of bacteria involved in the mineralization of Spartina anglica-derived organic matter.
\end{abstract}

KEY WORDS: Nematodes - Bacteria - Estuarine - Recruitment · Taxis · Chemotaxis · Microdistribution . Species succession

\section{INTRODUCTION}

The meiofauna of marine and estuarine sediments is almost invariably dominated by nematodes. Densities in fine-grained intertidal and shallow subtidal sediments average $10^{6} \mathrm{ind} . \mathrm{m}^{-2}$, representing a biomass of roughly 0.2 to $2 \mathrm{~g} \mathrm{C} \mathrm{m}^{-2}$ (Heip et al. 1985). An enigmatic feature of marine nematode communities is their often high species diversity. It is not uncommon to find 50 species in a $10 \mathrm{~cm}^{3}$ core, and, for example, some 800

·E-mail: tom.moens@rug.ac.be species have been reported for the North Sea alone (Vincx 1989). In the deep sea, diversity may even be considerably higher (Lambshead 1993). By contrast, studies trying to streamline this high diversity into functional groups or trophic guilds have arrived at a limited number of categories (Wieser 1953, Jensen 1987, Moens \& Vincx 1997). It has been inferred that nematodes are specialist feeders (Tietjen et al. 1970 , Tietjen \& Lee 1973, 1977), but observations on selected taxa of the different feeding guilds have indicated a mainly mechanistic food particle selection and significant opportunism (e.g. prey-switching) in the feeding behaviour of several species (Moens \& Vincx 1997). 
Meiofauna in general and nematodes in particular have a strongly heterogeneous small-scale distribution; the size of their patches may be considerably smaller than the surface area covered with the traditionally deployed $10 \mathrm{~cm}^{2}$ meiofauna cores (Findlay 1981, 1982). Lee et al. (1977) used a 'cafeteria' setup based on the multiple choice design of Gray (1966b) to demonstrate that food patches scattered around a central meiofauna inoculum attract strongly varying numbers of meiofauna and different meiofaunal taxa, depending on the type of food offered. They concluded that selective recruitment to food spots may be a major factor driving the heterogeneous field distribution of the meiofauna. In a similar approach, Trotter \& Webster (1984) demonstrated that 3 dominant nematode species from kelp holdfasts were differentially attracted to several types of bacterial and microalgal food. The preferences so illustrated revealed a good agreement between the seasonal abundance pattern of each nematode species and of its preferred food. Decaying organic matter has been shown to attract some nematode species and to repell others (Buerkel 1901, Gerlach 1977, Riemann 1986, Lorenzen et al. 1987, Prein 1988, Olafsson 1992). Gravid females of Metoncholaimus scissus strongly recruited to mycelia of certain marine fungi (Meyers \& Hopper 1966, 1967).

In a series of pioneering studies, Gray documented the role of bacteria in determining the horizontal distribution of some interstitial archiannelids, a gastrotrich, and a harpacticoid copepod, and demonstrated a highly differential attractiveness among bacteria from the meiofauna's natural habitat (Gray 1966a, b, $1967 \mathrm{a}$, b, 1968, Gray \& Johnson 1970). It was concluded that bacterial films on sand grains differentially attract meiofaunal organisms, and that the response of the meiofauna is mainly directed at characteristics of the bacterial cell wall, rather than to a product or products released by the bacteria into their environment (Gray \& Johnson 1970). Such a response would imply a tactile chemical sense' of the meiofauna as defined by Crisp \& Meadows (1963). Contrary to this interpretation are studies on mainly terrestrial and plant-parasitic nematodes exhibiting a malnly chemotactic response to a variety of inorganic ions, organic molecules, pheromones, bacteria, and bacteria- or degradation-associated compounds (see 'Discussion' for references).

The present study aims at elucidating the potential role of a taxis, i.e. a directed movement, towards patches of preferred food in determining the small-scale spatial heterogeneity in nematode abundance and species composition. This paper reports on the taxis of 4 monhysterid nematodes towards bacteria. Diplolaimelloides meyli Timm, 1966, Diplolaimella dievengatensis Jacobs et al. 1990, Monhystera species Bastian 1865, and Geomonhystera disjuncta (Bastian 1865) Jacobs 1987 all occur in a $1 \mathrm{~m}^{2}$ sampling quadrant at the edge of the Paulina salt marsh, situated near the mouth of the Westerschelde Estuary, SW Netherlands, where they are mainly associated with decaying plant material. They are all considered deposit feeders (Wieser 1953, Jensen 1987. Moens \& Vincx 1997), feeding predominantly on the bacterial flora associated with the plant detritus (Bouwman et al. 1984). A year-round field survey of selected microhabitats in the salt marsh (Moens unpubl.) suggests significant habitat overlap between the species. As such, they are potential competitors for food.

In this paper, we focus on differences in the response of different nematode species (1) to different strains of bacteria, (2) to bacteria sampled from differently aged cultures, (3) to different densities of bacteria, (4) to bacterial growth medium, and (5) to substances released by the bacteria. The first of these is studied in order to elucidate the potential of different species of bacteria-e.g. those associated with specific types of salt marsh detritus - to differentially attract nematodes. The second and third test the hypothesis that nematode species may preferentially respond to bacterial cues characteristic of specific stages of detritus decay. The fourth and fifth aim at a preliminary characterization of the nature of the nematode response. Furthermore, the hypothesis that any taxis will be influenced by the abiotic environment is tested using incubations under different temperature regimes.

\section{MATERIALS AND METHODS}

Cultivating the nematodes. A detailed description of the methods employed in the isolation, maintenance, and monospecific, agnotobiotic ${ }^{1}$ cultivation of the nematodes studied is given elsewhere (Moens \& Vincx 1998). Briefly, spot plates were prepared by the inoculation of small samples of plant litter (Spartina anglica and Fucus vesiculosus) and sediment from the Paulina salt marsh (Westerschelde Estuary, SW Netherlands) onto sloppy $(0.75 \%)$ bacto-agar layers prepared with modified Killian nutrient medium (von Thun 1966). Monospecific, agnotobiotic cultures of each species were established by manual transfer of a few tens of specimens from the spot plates to a $1 \%$ bacto-nutrient agar (bacto and nutrient agar in a weight/weight ratio of 4/1) dissolved in artificial seawater (ASW) (Dietrich \& Kalle 1957) with a salinity of 25 psu. Bacteria cotransferred from the spot plates served as food. Stocks were kept at $20^{\circ} \mathrm{C}$ in the dark. By the start of the presently reported experiments, Geomonhystera disjuncta had been in permanent culture for more than $6 \mathrm{mo}$, the other species for more than $1 \mathrm{yr}$.

'Containing unidentified associated (micro-)organisms 
The 4 nematode species can reach densities of hun dreds of individuals per $\mathrm{ml}$ of agar, and as a result of the intense microbial activity in the plates, the agar gradually becomes more fluid. This eventually results in (semi-)liquid cultures dominated by juveniles that do not fully mature anymore, probably as a result of crowding. When at this stage food is added as a dense suspension of Escherichia coli, growth briefly resumes, resulting in densely populated cultures dominated by adults and third (J3) and fourth (J4) stage juveniles. Aliquots of such cultures were used in all experiments with Diplolaimelloides meyli, Diplolaimella dievengatensis and Monhystera sp. Geomonhystera disjuncta were hand-picked or rinsed off from the surface of cultures.

Before experiments, nematode aliquots were washed with sucrose in a final concentration of $40 \%$ $(w / w)$ to remove most adhering bacteria and culture medium (Sulston \& Brenner 1974, modified according to pers. comm. of Dr J. Vanfleteren), subsequently rinsed 4 times in ASW, and finally resuspended in ASW. Streptomycin sulphate and benzylpenicillin were added in final concentrations of $5000 \mu \mathrm{g} \mathrm{ml}^{-1}$ and 5000 units $\mathrm{ml}^{-1}$, respectively, to block growth of bacteria still present in the nematode inocula. Aliquots from this nematode suspension were then used for experiments.

Cultivating the bacteria. In each of the experiments performed, 1 of the following 4 bacterial cultures were used: (1) A batch culture isolated from stocks of the nematode Diplolaimelloides meyli; this batch culture contained 4 bacterial strains (as determined from observations of colony morphology), 2 of which were dominant, grown in $2.5 \%$ heart infusion broth dissolved in A.SW with a salinity of 30 psu (buffered to a $\mathrm{pH}$ of 7.5 to 8 with $5 \mathrm{mM}$ Tris- $\mathrm{HCl}$ ). (2) Strain B1 was isolated from this batch culture using standard procedures and cultured on the same medium. Both batch cultures and B1 cultures were grown at room temperature in $250 \mathrm{ml}$ Erlenmeyer flasks on a rotary shaker. For experiments, aliquots of these bacterial cultures were pipetted onto quadrant plates (see 'General experimental design and statistical data analysis') Alternatively, bacteria were harvested from the cultures by centrifugation ( $15 \mathrm{~min}$ at $8000 \mathrm{rpm}$ [ $5200 \times \mathrm{g}]$ ) and subsequently rinsed 3 times with and resuspended in ASW. The supernatant obtained after the first centrifugation was also used for further tests.

(3) Stock cultures of the Gram-positive bacterium Halobacillus trueperi strain BTM1 and (4) the Gramnegative Escherichia colistrain LMG2092T were cultivated on $2 \%$ marine nutrient agar (Difco). For experiments, selected colonies of these bacteria were inoculated in marine broth (Difco) in $250 \mathrm{ml}$ Erlenmeyer flasks on a rotary shaker and allowed to grow for $24 \mathrm{~h}$ at $28^{\circ} \mathrm{C}$. Bacteria were then harvested by centrifugation and subsequently washed 3 times with and resuspended in physiological water (PW). The supernatant obtained after the first centrifugation was also used for experiments.

General experimental design and statistical data analysis. The experimental setup used in this study was a modified quadrant plate design (Fig. 1) coined from the quadrant plate design of Andrew \& Nicholas (1976) and from the cafeteria design of Trotter \& Webster (1984), which in turn are both modifications of Gray's (1966b, 1967a, b) multiple choice setup. Candidate attractants and controls were spotted crosswise around a central nematode inoculum on sloppy bactoagar layers. There was always a total of 4 spots surrounding the inoculum, including the candidate attractants and at least 1 control spot. The spots and inocula were 100 or $200 \mu \mathrm{l}$ aliquots of a candidate attractant, control or nematode culture, with an average distance between the centers and edges of the nematode inoculum and the test spots of 3.5 and $2.5 \mathrm{~cm}$, respectively.

Sloppy agar layers were prepared by pouring $12 \mathrm{ml}$ of a $0.5 \%$ bacto-agar (DifCo) into $9 \mathrm{~cm}$ diameter petri dishes exposed on a perfectly flat surface. The low agar concentration enabled the nematodes to easily penetrate the agar, as preliminary experiments proved this was important, particularly to Diplolaimella dievengatensis and Geomonhystera disjuncta. The nematodes were inoculated about $1 \mathrm{~h}$ after spotting the candidate attractants. The nematode inocula were allowed to evaporate for about $15 \mathrm{~min}$ under a laminar flow hood, because nematodes often were unable to escape the surface tension of the inoculum drop. The petri dishes were then incubated at $20^{\circ} \mathrm{C}$ in the dark, except when noted otherwise, and the numbers of nematodes in each spot as well as in the sectors between the spots (intersects) counted after $24 \mathrm{~h}$. Preliminary observations showed that the nematodes dispersed or moved towards an attractant after seconds or minutes, occasionally after a few hours, with a stable response almost invariably having been reached after $24 \mathrm{~h}$. Once inside a preferred spot, most nematodes tended to stay inside it or make only small excursions in its immediate vicinity (see also Andrew \& Nicholas 1976). A preliminary experiment was run to ascertain that the position and orientation of the petri dishes inside the incubator did not influence the dispersal of the nematodes.

All results have been expressed as relative \% of nematodes recovered from spots or intersects. Only the nematode \% inside candidate attractive spots (including the control spot[s]) were retained for statistical analysis, and the \% were adjusted to give composition, i.e. their cumulative abundance equals 100\%. As such, the weight of all replicates in a replicated statistical test 


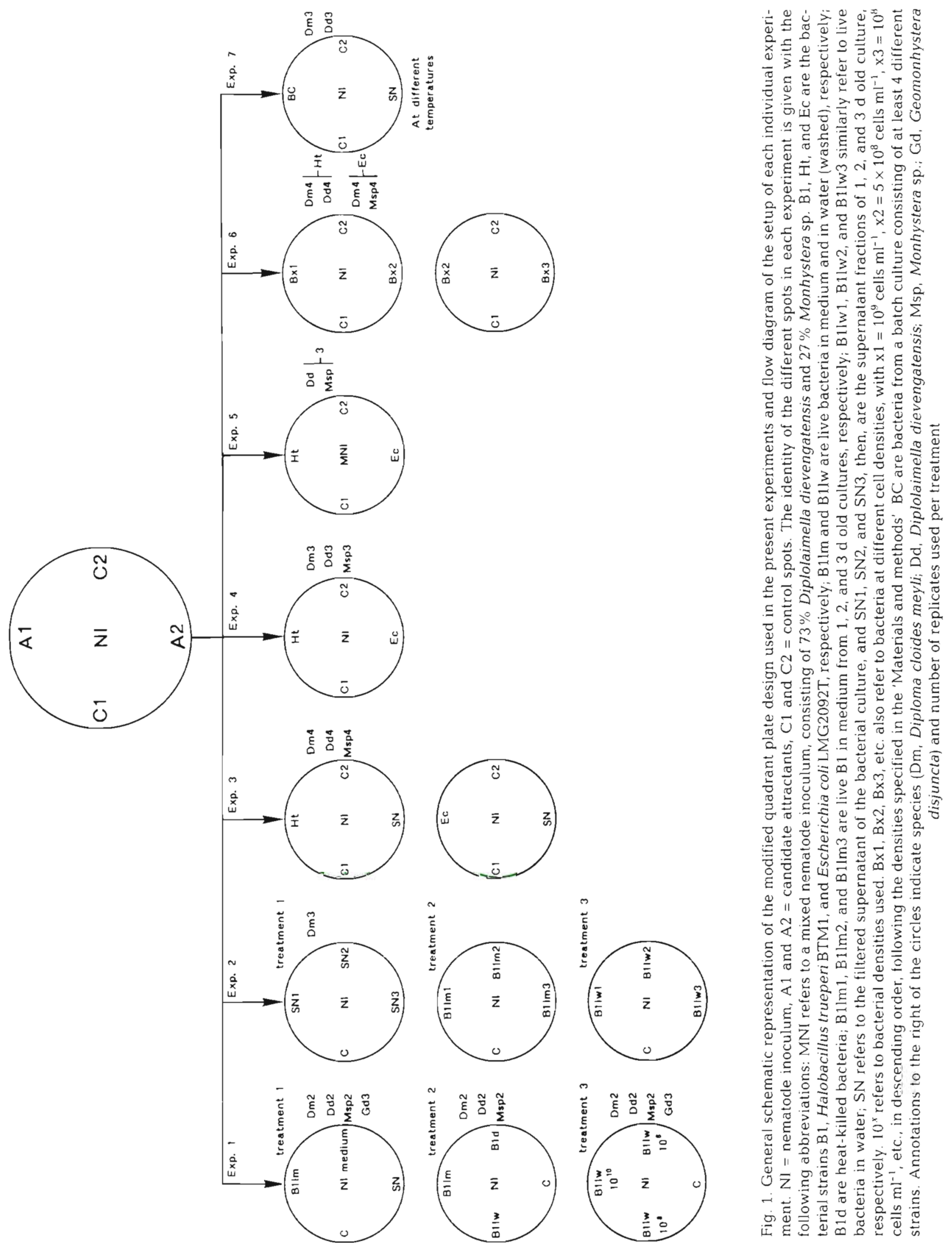


is equal. Replicated $G$-tests for goodness of fit to a chisquare distribution, i.e. with $25 \%$ of the nematodes inside each of the 4 spots, were performed in order to determine significant deviations from the expected $1 / 1 / 1 / 1$ distribution. Heterogeneity $G\left(G_{H}\right)$ was determined as an indication of whether the observed distributions differed among replicates of 1 treatment. Emphasis was, however, on the pooled $G\left(G_{p}\right)$, as a measure of overall deviation from the expected distribution over all replicates of 1 treatment (Sokal \& Rohlf 1995). Unplanned, pairwise comparisons were performed by computing $G_{\mathrm{p}}$ at a critical probability of $\alpha^{\prime}=\alpha / k$, with $k$ equal to the number of intended tests (Bonferroni approach, Sokal \& Rohlf 1995). Since each interspot comparison was potentially meaningful, these unplanned tests were performed at an $\alpha$ level of 0.005 $(<0.05 / 6)$, ensuring an experimentwise $\alpha$ of $<0.05$.

Response of the 4 monhysterid nematode species to the bacterial strain B1. Expt 1: Each nematode species was subjected to 3 different treatments (Fig. 1). In the first treatment, the 4 spots around the nematode inoculum were $200 \mu \mathrm{l}$ aliquots of (1) a $48 \mathrm{~h}$ old B1 culture (= live B1 in medium), (2) supernatant-filtered over a $0.22 \mu \mathrm{m}$ millipore filter - of the same B1 culture, (3) sterile heart infusion broth medium, and (4) sterile ASW of 30 psu. The second treatment consisted of a B1 culture spot and an ASW control as in the first series, a heat-killed $\left(1 \mathrm{~h}\right.$ at $\left.70^{\circ} \mathrm{C}\right)$ aliquot of the same B1 culture, and B1 washed and resuspended in ASW to remove culture medium. The third treatment had spots of B1 in ASW at densities of $10^{10}, 10^{8}$ and $10^{6}$ cells $\mathrm{ml}^{-1}$, respectively, and an ASW control.

Expt 2: The attraction of Diplolaimelloides meyli to strain B1 at different growth stages was tested using 3 treatments. The 4 spots surrounding the central nematode inoculum were $100 \mu$ l aliquots $\left(2 \times 10^{9}\right.$ cells $\mathrm{ml}^{-1}$ ) from cultures grown for 24,48 and $72 \mathrm{~h}$. In treatment 2 , these aliquots consisted of live B1 in medium. In treatment 3 , they were washed bacteria (= bacteria from that culture but resuspended in ASW), and in treatment 1 they consisted of culture supernatant. ASW was used as the control in all treatments (Fig 1).

Attraction to a Gram-positive and a Gram-negative bacterium. Expt 3: The attraction of Diplolaimelloides meyli, Monhystera sp. and Diplolaimella dievengatensis to the bacteria Halobacillus trueperi and Escherichia coli was studied. Geomonhystera disjuncta was omitted from this and all subsequent experiments, as well as from treatment 2 in Expt. 1, because of an infection of the stock cultures. For each nematode species, quadrant plates were spotted with $H$. trueperi in PW (= washed bacteria) and with the filtered culture supernatant at opposite sides, and with 2 spots of PW as controls, and incubated at $20^{\circ} \mathrm{C}$ in the dark for $24 \mathrm{~h}$. A second treatment was run with $E$. coli (Fig. 1)
Expt 4: Each petri dish was inoculated with a spot of washed Halobacillus trueperi and one of Escherichia coll at opposite sides of the nematode and with 2 control spots (Fig. 1) to directly infer any nematode preference for either bacterial species over the other. Bacterial inocula contained $2 \times 10^{8}$ cells $\mathrm{ml}^{-1}$ throughout this experiment.

Expt 5: The nematode species with the strongest relative preference for Halobacillus trueperi, i.e. Diplolaimella dievengatensis, and the one with the highest relative preference for Escherichia coli, i.e. Monhystera sp., were spotted in a mixed 2-species inoculum between opposing spots of washed $H$. trueperi and $E$. coli at equal cell densities $\left(3 \times 10^{8}\right.$ cells $\left.\mathrm{ml}^{-1}\right)$ (Fig. 1$)$. After $24 \mathrm{~h}$, the total number of each species in each bacterial spot was noted, as well as the relative proportions of both species in each spot.

Expt 6: The effect of bacterial density on the attractiveness of a spot of Escherichia coli to Diplolaimelloides meyli and Monhystera sp. was studied in the following way. For each nematode species a series of quadrant plates was prepared with spots of decreasing bacterial density. The first plate of such a series had a spot of $10^{9}$ and one of $5 \times 10^{8}$ cells $\mathrm{ml}^{-1}$ at opposite sides, as well as 2 control spots; the second had opposed spots of $5 \times 10^{8}$ and $10^{8}$ cells $\mathrm{ml}^{-1}$; the series was continued down to $10^{3}$ cells $\mathrm{ml}^{-1}$ with the following density pairs: $10^{8}$ and $10^{7}, 10^{7}$ and $10^{6}, 10^{6}$ and $10^{5}$, and $10^{5}$ and $10^{3}$ (Fig. 1). The effect of bacterial density on the attractiveness of $H$. trueperi to $D$. meyli and $D$. dievengatensis was tested in a parallel experiment.

Impact of temperature on the attraction of nematodes to their bacterial food. Expt 7: Aliquots of Diplolaimelloides meyli and of Diplolaimella dievengatensis were inoculated amidst $200 \mu \mathrm{l}$ spots of live bacteria in medium of a $48 \mathrm{~h}$ old batch culture, supernatant of this culture, and 2 ASW controls (Fig. 1). Three replicate petri dishes for each species were incubated in the dark at each of the following temperatures: $5,10,15$, 20 , and $25^{\circ} \mathrm{C}$. After 24 and $48 \mathrm{~h}$, the nematode numbers inside each spot, in the intersects, and in the inoculum spot were counted in order to assess any temperature-induced differences in the taxis response and in the activity level of the nematodes.

\section{RESULTS}

\section{Response of the 4 monhysterid nematode species to the bacterial strain B1}

$$
\text { Expt } 1
$$

The results of the experiments on the attraction of the 4 nematode species to the bacterial strain B1 are 
Table 1. Relative recruitment percentages of the 4 monhysterid nematode species to the unidentified bacterial strain B1. Averages and standard deviations of 2 or 3 replicates per treatment are given. nd = not determined. Washed bacteria are live culture aliquots washed and resuspended in ASW (see 'Materials and methods'). All bacterial spots had cell densities of $10^{10}$ cells ml ${ }^{-1}$, except for bacteria $1 / 100$ and bacteria $1 / 10000$, which had densities of $10^{8}$ and $10^{6}$ cells $\mathrm{ml}^{-1}$, respectively

\begin{tabular}{|c|c|c|c|c|c|c|}
\hline Treatment 1 & $\begin{array}{c}\text { Live } \\
\text { bacteria }\end{array}$ & $\begin{array}{l}\text { Bacterial } \\
\text { medium }\end{array}$ & Supernatant & Control & $\begin{array}{c}\text { Total } \\
\text { intersects }\end{array}$ & $\begin{array}{l}\text { Central } \\
\text { inoculum }\end{array}$ \\
\hline Monhystera sp. & $41.5 \pm 2.12$ & $0 \pm 0$ & $5 \pm 4.24$ & $13 \pm 2.83$ & $21.29 \pm 4.39$ & $19.42 \pm 0.14$ \\
\hline Diplolaimelloides meyli & $37 \pm 2.83$ & $9.5 \pm 4.95$ & $16 \pm 4.24$ & $9.5 \pm 0.71$ & $23.77 \pm 2.14$ & $4.6 \pm 0.97$ \\
\hline Diploiaimella dievengatensis & $12.5 \pm 0.71$ & $1 \pm 1.41$ & $12 \pm 1.41$ & $17 \pm 4.24$ & $17.69 \pm 10.08$ & $36.45 \pm 14.33$ \\
\hline Geomonhystera disjuncta & $27.2 \pm 8.3$ & $1.5 \pm 1.7$ & $7.4 \pm 3$ & $14 \pm 8.2$ & $7.6 \pm 4.7$ & $39.3 \pm 10.5$ \\
\hline Treatment 2 & $\begin{array}{l}\text { Live } \\
\text { bacteria }\end{array}$ & $\begin{array}{l}\text { Heat-killed } \\
\text { bacteria }\end{array}$ & $\begin{array}{l}\text { Washed } \\
\text { bacteria }\end{array}$ & Control & $\begin{array}{c}\text { Total } \\
\text { intersects }\end{array}$ & $\begin{array}{l}\text { Central } \\
\text { inoculum }\end{array}$ \\
\hline Monhystera sp. & $10 \pm 4.24$ & $3 \pm 2.83$ & $27 \pm 2.83$ & $7.5 \pm 3.54$ & $8.31 \pm 0.18$ & $43.81 \pm 2.13$ \\
\hline Diplolaimelloides meyli & $23.5 \pm 0.71$ & $35.5 \pm 2.12$ & $20 \pm 2.83$ & $5 \pm 0$ & $13.06 \pm 1.68$ & $3.49 \pm 1.78$ \\
\hline $\begin{array}{l}\text { Diplolaimella dievengatensis } \\
\text { Geomonhystera disjuncta }\end{array}$ & $\begin{array}{l}13.5 \pm 16.26 \\
\text { nd }\end{array}$ & $\begin{array}{l}0 \pm 0 \\
\text { nd }\end{array}$ & $\begin{array}{l}7.5 \pm 17.68 \\
\text { nd }\end{array}$ & $\begin{array}{l}4.5 \pm 3.54 \\
\text { nd }\end{array}$ & $\begin{array}{c}11.45 \pm 8.41 \\
\text { nd }\end{array}$ & $\begin{array}{c}42.14 \pm 14.19 \\
\text { nd }\end{array}$ \\
\hline Treatment 3 & $\begin{array}{l}\text { Washed } \\
\text { bacteria }\end{array}$ & $\begin{array}{c}\text { Bacteria } \\
1 / 100\end{array}$ & $\begin{array}{l}\text { Bacteria } \\
1 / 10000\end{array}$ & Control & $\begin{array}{c}\text { Total } \\
\text { intersects }\end{array}$ & $\begin{array}{l}\text { Central } \\
\text { inoculum }\end{array}$ \\
\hline Monhystera sp. & $37.5 \pm 12.02$ & $13 \pm 9.9$ & $10.5 \pm 2.12$ & $4.5 \pm 0.71$ & $3.35 \pm 1.28$ & $31.59 \pm 7.06$ \\
\hline Diplolaimelloides meyli & $33 \pm 11.31$ & $23 \pm 4.24$ & $14.5 \pm 4.95$ & $12 \pm 5.66$ & $10.28 \pm 0.02$ & $5.58 \pm 2.51$ \\
\hline Diplolaimella dievengatensis & $14.5 \pm 4.95$ & $15.5 \pm 7.78$ & $24.5 \pm 7.78$ & $8.5 \pm 7.78$ & $7.13 \pm 0.65$ & $29.8 \pm 1 . \overline{7} 4$ \\
\hline Geomonhystera disjuncta & $33.5 \pm 13.03$ & $13.7 \pm 7.27$ & $9.1 \pm 1.94$ & $7.1 \pm 2.05$ & $13.6 \pm 3.91$ & $23 \pm 7.11$ \\
\hline
\end{tabular}

summarized in Table 1. In the first treatment, live bacteria in medium attracted significantly higher numbers of Monhystera sp., Diplolaimelloides meyli and Geomonhystera disjuncta, but not of Diplolaimella dievengatensis, than did control spots ( $\mathrm{p} \ll 0.001)$. D. meyli was the single species not to be repelled by bacterial growth medium and to be attracted to supernatant of bacterial culture. The attractiveness of the supernatant was lost when diluted with an equal volume of ASW, or after heating $\left(1 \mathrm{~h}\right.$ at $\left.60^{\circ} \mathrm{C}\right)$ or autoclaving $\left(15 \mathrm{~min}\right.$. at $1.1 \mathrm{~atm}$ and $120^{\circ} \mathrm{C}$ ) (data not shown). In the second treatment, washed bacteria were more attractive to Monhystera sp. than unwashed culture aliquots $(p \ll 0.001)$, while both attracted similar numbers of $D$. meyli. The latter species, however, significantly preferred heat-killed over live bacterid $(p \&$ 0.001 ). The response in $D$. dievengatensis was highly heterogeneous among replicates $(p \ll 0.001)$, but this species was repelled by heat-killed bacterial cells in both replicates $(p<0.001)$. In the third treatment, the highest cell density attracted significantly more nematodes than did lower densities in all nematodes except $D$. dievengatensis. The response was density dependent over the entire range of observed densities in $D$. meyli $(\mathrm{p} \ll 0.001$ ), while the response of Monhystera $\mathrm{sp}$, and $\mathrm{G}$, disjuncta to the lower 2 densities did not differ $(p>0.05)$. $D$. dievengatensis preferred the lowest cell density over the 2 higher ones $(p<0.005)$.
Expt 2

Live B1 in medium from $3 \mathrm{~d}$ old culture attracted more Diplolaimelloides meyli than did bacteria from $2 \mathrm{~d}$ old cultures ( $p<0.005$ ), but differences between 1 and $2 \mathrm{~d}$ old or between 1 and 3 d old culture aliquots were not significant (Fig. 2). No differences were

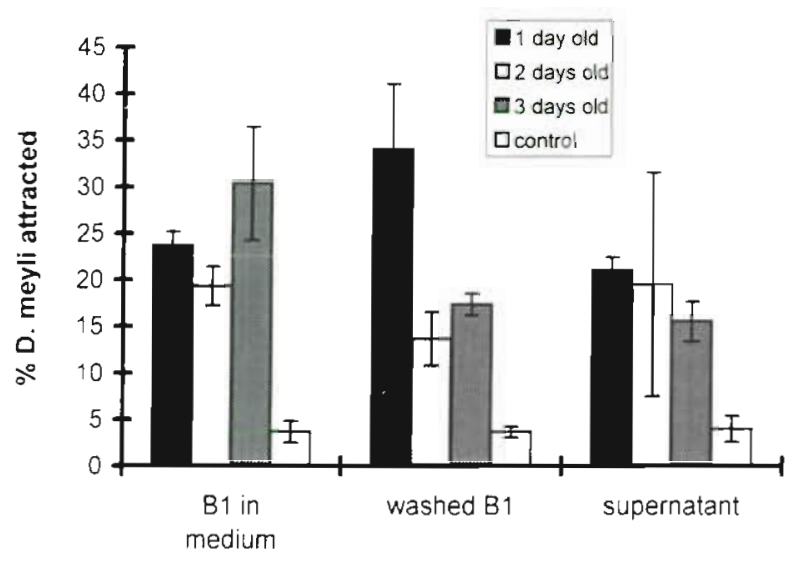

Fig. 2. Diplolaimelloides meyli. Effect of bacterial culture age on the attractiveness of culture aliquots, of washed bacteria, and of filtered culture supernatant to the nematode. Means and standard deviations of 3 replicates per treatment are given 

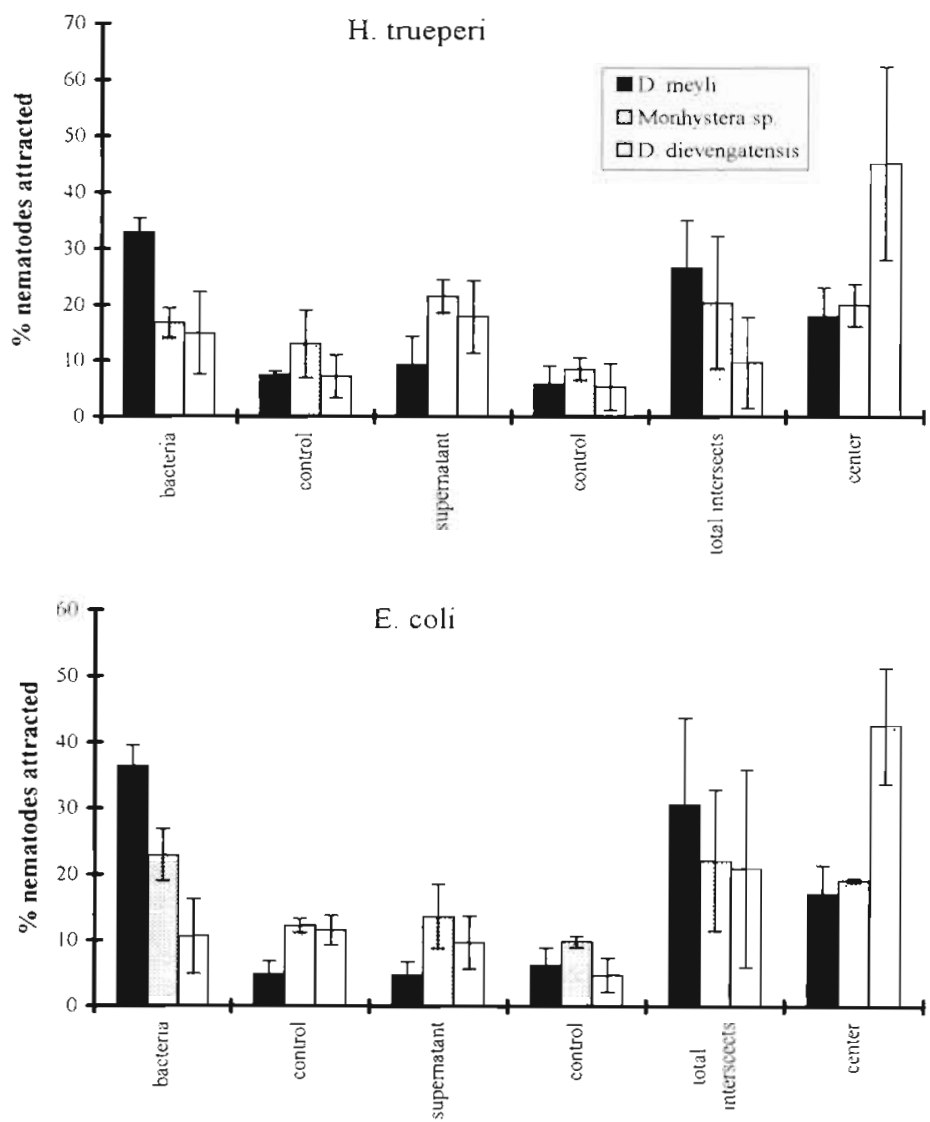

Fig. 3. Diplolaimelloides meyli, Monhystera sp. and Diplolaimella dievengatensis. Relative recruitment percentages of the 3 monhysterid nematode species to cells and filtered supernatant of cultures of the bacteria Halobacillus trueperi and Escherichia coli. Means and standard deviations of 4 replicates per treatment are given. See 'Materials and methods' for details on treatments, incubation conditions and bacterial cell densities used
Expt 4

When simultaneously presented with the 2 species of bacteria, Diplolaimelloides meyli was equally attracted to both; Diplolaimella dievengatensis significantly $(p \ll 0.001)$ preferred Halobacillus trueperi over Escherichia coli, while Monhystera sp. exhibited the opposite preference ( $p \ll 0.001$ ) (Fig. 4). In the former 2 species, there was significant heterogeneity among replicates $(p<0.005)$. Pooled data suggested a preference of $D$. meyli for $H$. trueperi over E. Coli, but omission of the deviant replicate from the analysis overruled this effect. Replicate heterogeneity did not affect the observed preference of $D$. dievengatensis for $H$. trueperi

\section{Expt 5}

In a mixed inoculum of Diplolaimella dievengatensis and Monhystera sp. simultaneously offered Halobacillus trueperi and Escherichia coli, similar numbers of Monhystera sp. were found in both bacterial spots. $D$. dievengatensis, on the other hand, was 3 times more abundant in spots of $H$. trueperi than in spots of E. coli (Fig. 5). As a consequence, the relative percentages of $D$. dievengatensis and Monhystera sp., which in the inoculum were 73 and 27, respectively, decreased to 62.8 for $D$. dievengatensis in E. coli spots and to 22.8 found between the numbers of $D$. meyli reaching supernatant of 1,2 or $3 \mathrm{~d}$ old cultures. However, washed bacteria from $1 \mathrm{~d}$ old culture attracted twice as many $D$. meyli than did bacteria from 2 and $3 \mathrm{~d}$ old cultures ( $\mathrm{p} \ll 0.001$ ) (Fig. 2).

\section{Attraction towards a Gram-positive and a Gram- negative bacterium}

\section{Expt 3}

Diplolaimelloides meyli moved to both washed Halobacillus trueperi and Escherichia coli, but not to their respective supernatant fractions (Fig. 3). D. dievengatensis showed a small but significant ( $p \ll 0.001$ ) positive response to both cells and supernatant of $H$. trueperi but not of $E$. coli. By contrast, Monhystera sp. reacted only to $E$. coli cells.

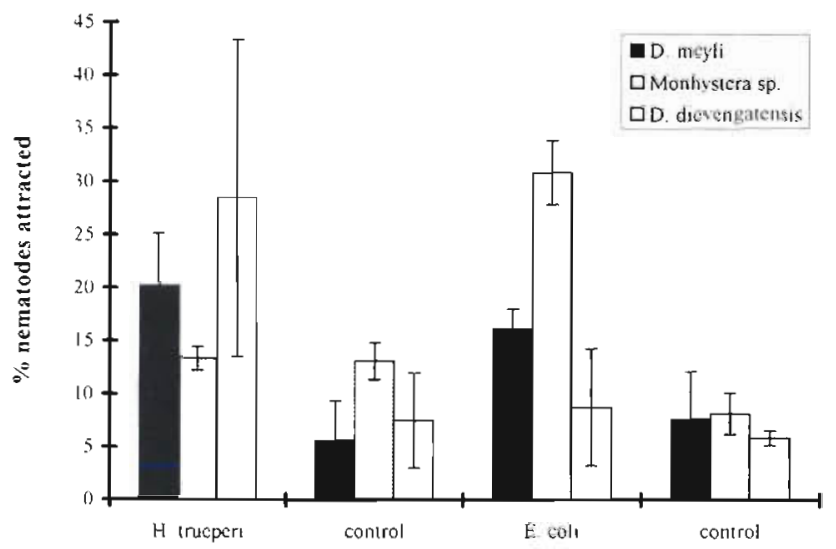

Fig. 4. Diplolaimelloides meyli, Monhystera sp. and Diplolaimella dievengatensis. Relative recruitment percentages of the 3 monhysterid nematode species to the bacteria Halobacillus trueperi and Escherichia coli offered simultaneously. Data are means and standard deviations of 4 replicates per treatment. See 'Materials and methods' for details on treatments, incubation conditions and bacterial cell densities used 

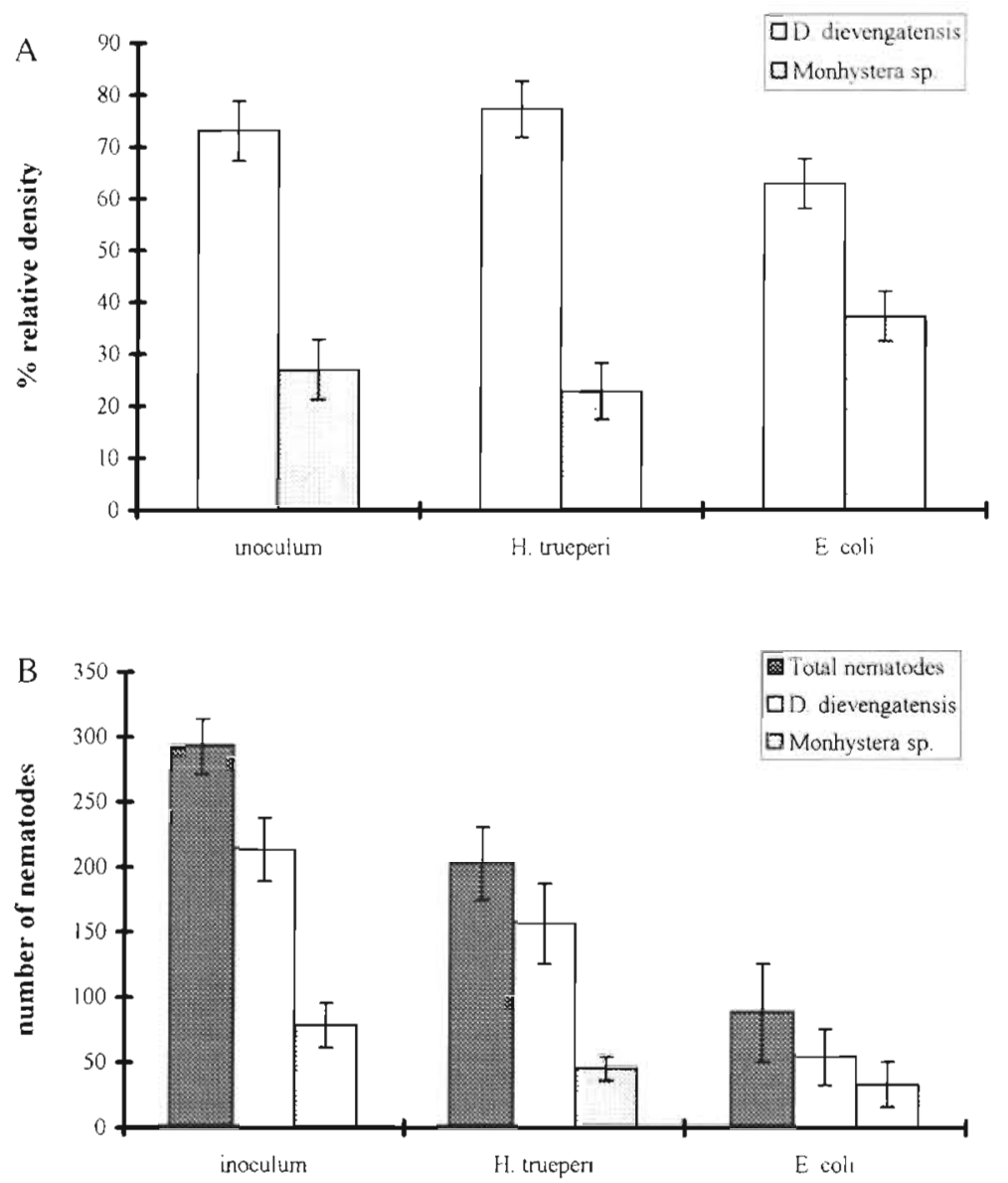

Fig. 5. Diplolaimella dievengatensis and Monhystera sp. (A) Relative densities and (B) absolute numbers of the nematodes inside spots of the bacteria Halobacillus trueperi and Escherichia coli in incubations with mixed inocula of both nematodes between 2 bacterial spots at opposite sides. Means and standard deviations of 3 replicates are shown

for Monhystera sp. in spots of $H$. trueperi, and increased to 77.2 for $D$. dievengatensis in spots of $H$. trueperi and to 37.2 for Monhystera sp. in spots of $E$. coli. The differences between relative nematode abundances in bacterial spots were significant $(\mathrm{p}<$ $0.005)$, as were the relative depletion of $D$. dievengatensis and the relative enrichment of Monhysterasp. in the $E$. coli spots compared to the inoculum ( $\mathrm{p}<$ 0.001 ). The percentage increase and decrease of $D$. dievengatensis and Monhystera sp. respectively, in the $H$. trueperi spots relative to the inoculum, though occurring in all 3 replicates, was not statistically significant $(p>0.05)$.

\section{Expt 6}

In trials with different densities of bacterial cells, Diplolaimelloides meyli consistently preferred the highest cell density $\left(10^{9}\right.$ cells $\left.\mathrm{ml}^{-1}\right)$ over lower ones (Fig. 6). The response was, however, not entirely density dependent over the whole range of densities tested, with a fairly density-independent attraction in the intervals of $10^{8}$ to $5 \times 10^{8}$ cells $\mathrm{ml}^{-1}$ and $10^{3}$ to $10^{7}$ cells $\mathrm{ml}^{-1}$. A sharp decline at densities below $10^{8}$ cells $\mathrm{ml}^{-1}$ was obvious. Diplolaimella dievengatensis, however, preferred a cell density of $5 \times 10^{8} \mathrm{ml}^{-1}$ over the higher $\left(10^{9}\right)$ and lower ones. The rest of its response was broadly similar to that of $D$. meyli, with a fairly density-independent response in similar intervals, and with a steep decline at the transition from $10^{8}$ to $10^{7}$ cells $\mathrm{ml}^{-1}$ (Fig. 6). By contrast, Monhystera sp. showed a density-dependent response over the whole interval tested, with peak numbers reaching spots of $10^{7}$ Escherichia coli $\mathrm{ml}^{-1}$; higher and lower bacterial densities recruited less Monhystera sp. (Fig. 6).

\section{Impact of temperature on the attraction of nematodes to their bacterial food}

\section{Expt 7}

After $24 \mathrm{~h}$, the respective percentages of nematodes that had moved out of the inoculum spot at $5,10,15,20$, and $25^{\circ} \mathrm{C}$ were approximately $2,20,20,50$, and $70 \%$ for Diplolaimelloides meyli and only $0,4,12,12$, and $1.2 \%$ for Diplolaimella dievengatensis (data not shown). In the latter species, however, the inocula had not evaporated and many individuals were at the edges of the drops, unable to escape the surface tension. After $48 \mathrm{~h}$, the respective percentages were approximately $5,65,75$, 90 , and more than $95 \%$ for D. meyli, and less than 1,5 , 10,40 , and $70 \%$ for $D$. dievengatensis (Fig. 7). A parallel response was noted for the numbers of $D$. meyli inside the bacterial spots after $24 \mathrm{~h}_{\mathrm{i}}$ after $48 \mathrm{~h}$, however, half of the nematodes had reached the bacterial spots at all temperatures from 10 to $20^{\circ} \mathrm{C}$. At 5 and $25^{\circ} \mathrm{C}$, this was less than 5 and more than $75 \%$, respectively. In $D$. dievengatensis, less than $10 \%$ of the nematodes had reached the bacterial spots at temperatures up to $15^{\circ} \mathrm{C}$, even after $48 \mathrm{~h}$, and the bacterial spots were not significantly more attractive than were the controls. At 20 and $25^{\circ} \mathrm{C}$, however, approximately 35 and $60 \%$ of the nematodes were inside the bacterial spots after $48 \mathrm{~h}$, while the controls at these temperatures contained equal numbers of nematodes as those at the lower temperatures. 


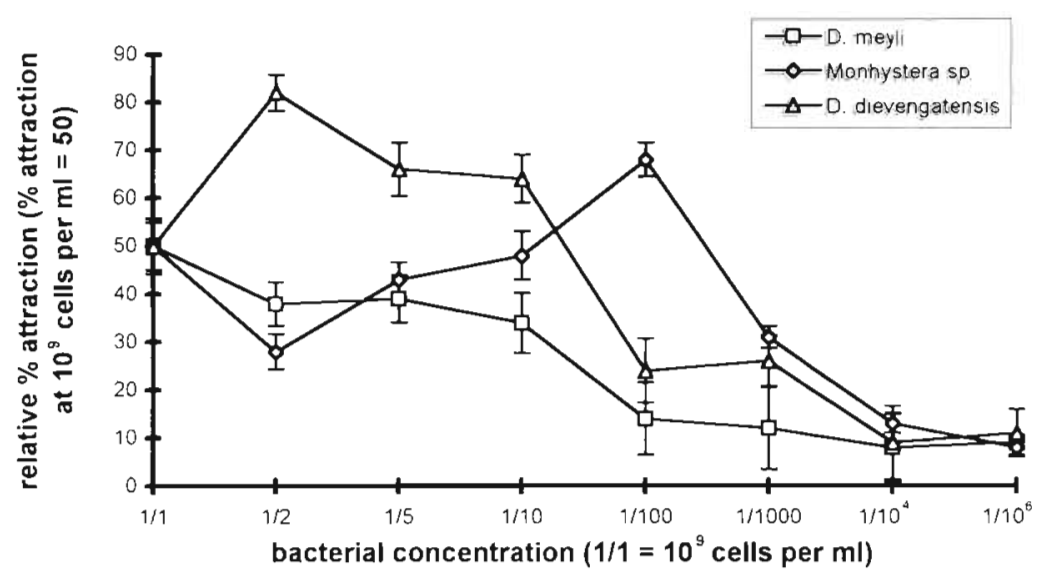

Fig. 6. Diplolaimelloides meyli, Monhystera sp. and Diplolaimella dievengatensis. Influence of cell density on the recruitment of the 3 nematode species to bacterial spots. Recruitment at the highest cell density was normalised to $50 \%$. In reality, it averaged 57,24 , and $24 \%$ in $D$. meyli, Monhystera sp., and $D$. dievengatensis, respectively. Recruitment percentages at the lower cell densities were extrapolated by comparison of data at a particular cell density to the mean recruitment at the previous density, with densities ranked from highest to lowest. Each data point represents the mean of 3 replicates. Error bars show the variance as a percentage of the mean. Since in all but the highest and lowest cell densities, 2 separate series of 3 replicates each were counted, the highest of both variances is shown
In a first experiment, we show that the bacterial strain B1 is attractive to all 4 monhysterid nematodes tested, but that the conditions under which this bacterium attracts nematodes largely differ. This highly differential response suggests that even 1 single bacterial species might be able to influence a community of the 4 nematodes studied to form patches of at least 3 different relative species compositions, depending on the 'condition' of the bacterial food. The observation that Diplolaimelloides meyli responded differently to bacteria sampled from cultures of different age further supports the potential of bacteria in different phases of growth to differentially attract nematodes. Cells from cultures in exponential growth phase are preferred over cells from older cultures by $D$. meyli. Evidence for an impact of bacterial (nutritional) status on the migration of nematodes was also pre-

\section{DISCUSSION}

A considerable body of literature exists on the response of mainly plant-parasitic and terrestrial nematodes to a variety of external stimuli, including electrical, mechanical and chemical stimuli and factors such as temperature and light (reviews in Croll 1970a, Dusenbery 1980, Coomans \& De Grisse 1981, Huettel 1986, Perry 1996). Analogous information on marine or brackish-water nematodes is, however, scant, and limited to observations on the attractiveness of $\mathrm{CO}_{2}$ to Adoncholaimus thalassophygas (Riemann \& Schrage 1988 ) and the recruitment of different major meiofaunal taxa or different nematode species, belonging to different feeding types, to patches of candidate food or towards sediment impregnated with different species of bacteria or unicellular algae (see 'Introduction' for references). This study demonstrates a highly species-specific marine nematode response to food and shows that one candidate food organism may be, depending on its condition, attractive, unattractive or even repulsive to the same nematode species.

Fig. 7. Diplolaimella dievengatensis and Diplolaimelloides meyli. Recruitment response of nematodes to inocula of the bacteria Halobacillus trueperi at different temperatures and after a $48 \mathrm{~h}$ incubation. Data are averages and standard deviations of 3 replicates
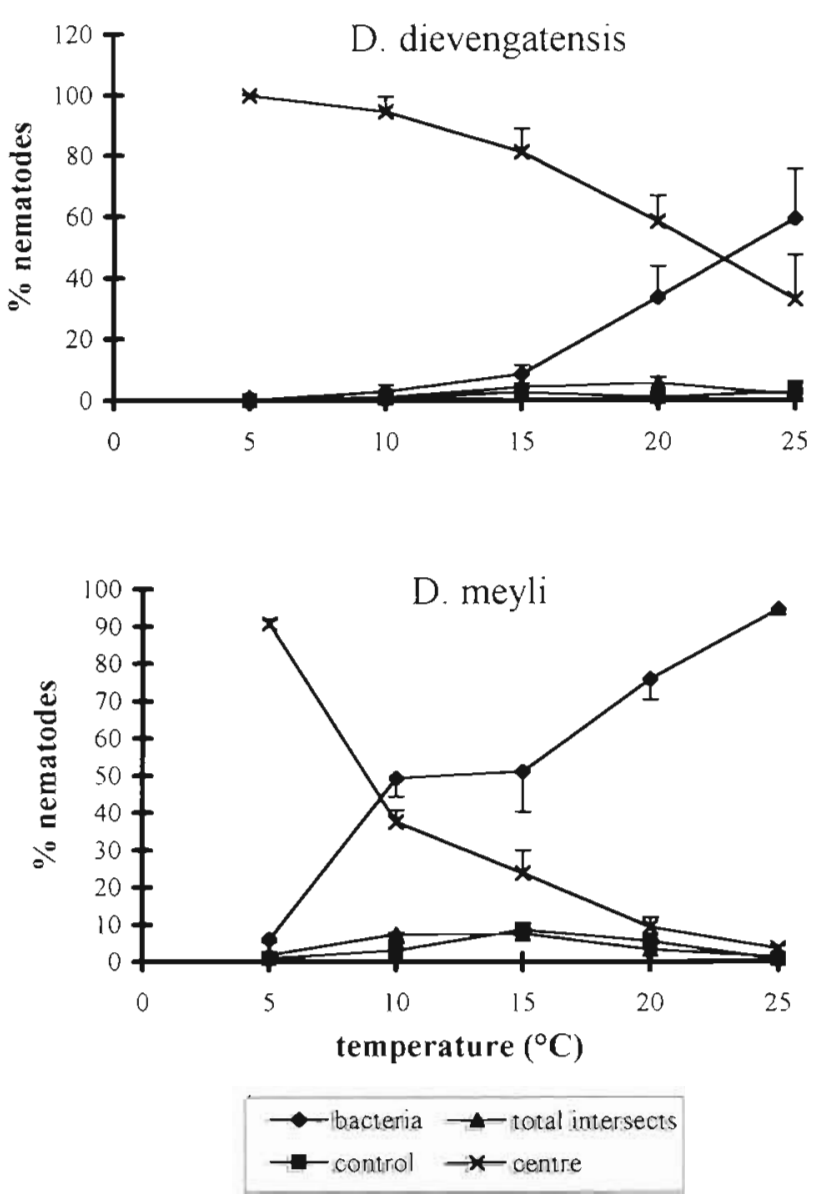
sented for the terrestrial Caenorhabditis elegans (Grewal \& Wright 1992).

In a second step, we focused on the response of nematodes to different species of bacteria. Three different types of response were noted for the 3 Monhysteridae studied no clear preference (Diplolaimelloides meyli), a preference for the Gram-negative bacterial strain over the Gram-positive one (Monhystera sp.), and the reverse (Diplolaimella dievengatensis). In summary, Halobacillus trueperi was attractive to all 3 Monhysteridae, but was the preferred source for only 1; Escherichia coli elicited a positive response from only 2 nematode species, and was the preferred source for 1 of these. A differential attractiveness of different bacterial species to terrestrial nematodes (Andrew \& Nicholas 1976, Jansson \& Nordbring-Hertz 1983, Grewal \& Wright 1992), and to free-living stages of the insectparasitic Neoaplectana carpocapsae (Pye \& Burman 1981) has been noted previously. Caenorhabditis elegans showed either a strong, an intermediate or a weak positive response to different bacteria and was repelled by others (Andrew \& Nicholas 1976, Grewal \& Wright 1992). However, none of the cited studies tested for the degree of response or preference in multiple choice experiments with 2 or more strains offered simultaneously, nor were bacteria standardized to cell densities. This study therefore eliminates the possibility that the observed preferences might be due to a density-dependent response. However, there still remains a chance that the choice of a non-specific growth medium for the 2 bacterial strains could have affected the (nutritional) quality of the bacterial populations in our experiments, and as such influenced their attractiveness to nematodes.

Surprisingly, in tests with a mixed nematode inoculum consisting of Diplolaimella dievengatensis and Monhystera sp, the latter species did not exhibit the same preference for Escherichia coli over Halobacillus trueperi that was observed in monospecific nematode inocula. $D$. dievengatensis, on the other hand, did show the same pattern of response. We repeated this experiment with observations of the nematodes' migration after shorter incubations, and found that $D$. dievengatensis responded more rapidly to its preferred source (i.e. H. trueperi), while Monhystera sp. started migrating somewhat later. Initially, this migration was mainly directed versus the $E$. coli inoculum, but many individuals reversed before reaching this spot and started migrating in the opposite direction. We suggest that the tracks of $D$. dievengatensis in some way influenced Monhystera sp., setting out a pattern that directed a larger-than-expected fraction of this species' inoculum to the $H$. trueperi spot. Inspite of this, the hypothesis that different bacterial spots would be colonised by differently composed nematode assem- blages was corroborated by our results: $D$. dievengatensis increased its dominance over Monhystera sp. in the $H$. trueperi spots, but decreased relative to Monhystera sp. in E. coli spots. In addition, the total numbers of nematodes reaching food spots heavily depended on the nature of the bacteria, with $H$. trueperi invariably attracting far higher nematode numbers than $E$. coli. While previous studies have already reported on the differential potency of a number of bacterial strains to attract Caenorhabditis elegans (see above), the present results demonstrate that 1 bacterial strain can at the same time elicit a positive response from one nematode, but not from another, closely related species. The observed preferences are unlikely to relate to preferences for either Grampositive or Gram-negative bacteria, since, for example $D$. dievengatensis, the species with the most pronounced preference for $H$. trueperi, has successfully been cultivated on diets of Gram-negative bacteria (Vranken et al. 1984).

Gray (1968) found no significant influence of bacterial density on the attractiveness of bacteria to the harpacticoid Leptastacus constrictus, while Gray \& Johnson (1970) did note a significant correlation between the number of attractive bacteria and the response of the gastrotrich Turbanella hyalina. The differential density-dependent response of the 3 nematodes used in our experiments to bacteria offers an attractive basis for explaining observed microhabitat preferences in terms of a succession of species on detritus in different stages of decay. As such, Diplolaimelloides meyli could somewhat presumptuously be considered as the species that may most readily respond to the early breakdown of plant litter, at a stage where concentrations of highly labile organic carbon and correspondingly high densities of bacteria are available. Diplolaimella dievengatensis and Monhystera sp. might then be envisaged as preferentially associated with later stages of leaf litter decay, i.e. with generally more refractory material and lower overall bacterial densities. Although our results provide no direct evidence for this relation, it is noteworthy that in situ, $D$. meyli is most abundant on decaying leaves still attached to the stems of Spartina anglica and other macrophytes, whereas $D$. dievengatensis and Monhystera sp. are more typical of the sediment around the roots of macrophytes, where they could be associated with the burial of plant litter. Geomonhystera disjuncta takes a position that is more similar to that of $D$. meyli, but prevails at lower temperatures (Moens unpubl.). It is also interesting to note that in monoxenic cultures of $G$. disjuncta and $D$. dievengatensis on the bacterial strain Alteromonas haloplanktis ISC $_{21}$ the former nematode needed high food levels, whereas the latter (erroneously referred to as Monhystera microphthalma 
in the original article) thrived on cell densities as low as $10^{6}$ to $10^{7}$ bacteria $\mathrm{ml}^{-1}$ (Vranken et al. 1984). Furthermore, the density-dependent response also indicates that the mere presence of a bacterial cue may be insufficient to trigger a nematode response: not only may the concentration of the stimulant be too low, it may also be too high.

It is by no means surprising to find that both the overall motility and the taxis of nematodes towards bacteria are strongly dependent on temperature. In general, the activity pattern of both species studied agrees well with patterns of temperature dependence as established from life cycle studies (Vranken 1985, for Diplolaimella dievengatensis; Moens unpubl. for Diplolaimelloides meyli) and from measurements of respiration (Moens unpubl.). All these data point at temperature optima in between 20 and $30^{\circ} \mathrm{C}$ for both species, with $D$. dievengatensis perhaps preferring slightly more elevated temperatures than $D$. meyli. Whereas both nematodes appear to have a similar temperature optimum, their activity at lower temperatures (up to $15^{\circ} \mathrm{C}$ ) as revealed by their migration away from the inoculum spot differs, with $D$. meyli remaining more motile than $D$. dievengatensis at 10 to $15^{\circ} \mathrm{C}$. However, since similar numbers of nematodes were recovered from control spots and intersects at all temperatures after a $48 \mathrm{~h}$ incubation, the distinctly higher numbers and proportions of nematodes inside bacterial spots at the higher temperatures suggest that the efficacy with which both nematodes respond to the bacterial spots is also temperature dependent. This can be explained either by a better perception by the nematodes of the bacterial stimulus, or alternatively by an increased stimulus production by the bacteria in the plates.

This paper demonstrates that free-living marine nematodes migrate in a directed way towards patches of food. In the absence of an attractive source, nematodes showed a random movement on and in the agar. Deviations from this 'random walk' behaviour consisted of clustering in groups of several tens of individuals in the inoculum spot or migration of adult males to female J4 and adults. Clustering of nematodes in aqueous suspensions has been noted previously and has been ascribed mainly to mechanistic interactions among individuals in dense suspensions (Doncaster \& Webster 1968, Croll 1970b); in our experiments, Diplolaimella dievengatensis showed the strongest tendency to aggregate, probably because the $D$. dievengatensis inocula contained on average the highest nematode densities. Consequently, the overall response in $D$. dievengatensis was less than in the other nematodes studied.

There is a general consensus, based on morphological and experimental evidence, that chemotactic fac- tors emanating from prey or host organisms govern the primary food-finding mechanisms in nematodes (Croll \& Sukhdeo 1981, Zuckerman \& Jansson 1984); both 'taste' (most studies) and 'smell' (Bargmann et al. 1993) are involved in this chemotaxis. From the present observations on the nematodes' migration up bacterial cue gradients, it is likely that the recruitment in our experiments also resulted from a chemotactic response, and, since the time allowed for the establishment of gradients emanating from the attractive spots was relatively short (sometimes less than $1 \mathrm{~h}$ ) and the nematodes' response often instantaneous, both soluble and volatile substances may have been involved. Nevertheless, the nature of the stimulus or stimuli that guide bacteriophagous nematodes to their food is hitherto unknown. The only bacteria-associated semiochemical of which the involvement in nematode chemotaxis has repeatedly been demonstrated is $\mathrm{CO}_{2}$ (Klingler 1965, Edmunds \& Mai 1967. Croll 1970a, Dusenbery 1974, Pline \& Dusenbery 1987, Riemann \& Schrage 1988). The attraction of free-living nematodes to a variety of inorganic ions (Ward 1973, Dusenbery 1974, 1976a), cyclic nucleotides (Ward 1973), and other organic compounds (Dusenbery 1975, 1976b) has been documented. A remarkable specificity of the response has been noted, e.g. D-tryptophan repelled Caenorhabditis elegans (Dusenbery 1975) and electrophysiologically stimulated the parasitic Syngamus trachea (Riga et al. 1995), while L-tryptophan elicited no response from C. elegans (Dusenbery 1975).

Although observations of the nematodes' behaviour in our experiments are highly suggestive of a true taxis response, the possibility of a random food-finding strategy where nematodes stay inside a suitable food spot after a chance encounter cannot be entirely excluded on the basis of this type of experiment alone. In a heterogeneous environment such as the benthos, a random food-finding strategy would be disadvantageous, particularly in organisms with an overall low vagility (White 1978). Even in organically enriched sediments of the Westerschelde Estuary, on average less than $3 \%$ of the sediment consists of organic matter, of which only part is a potential food source for the meiofauna. The difficulties in monoxenically rearing marine bacteriophagous or herbivorous species (see Moens \& Vincx 1998 for a review) are evidence of highly specific nutritional requirements, which are met by only a few food organisms, and the efficient finding and recognition of these suitable foods can therefore be considered vital to the nematodes' reproductive success.

The assay method used in our experiments is a rapid and suitable method for primary assessment of the response of many marine and brackish-water nematodes, be they cultivated or extracted from sediment 
samples, to a variety of candidate food sources. It is, however, much less applicable when aiming at the identification of particular single stimuli involved in the nematode response. For that purpose, individual nematodes need to be studied in a proper gradient of the stimulus. Candidate stimuli can preferentially be administered to the center of a petri dish containing a homogeneous agar or sephadex layer, and after appropriate time has been allowed for the establishment of a radial gradient, single nematodes can be inoculated to the edges of the dish and their response noted (Ward 1973, Riga \& Webster 1992). Additional information on the nematodes' response can be obtained from detailed observations of their migration, e.g. by photographing nematode tracks (Riddle \& Bird 1985, Riga \& Webster 1992) or by video-monitoring of their movement (Dusenbery 1983, 1992, Pline \& Dusenbery 1987. Anderson et al. 1997a). Totally different approaches towards the study of nematode responses to chemicals have been countercurrent separation (Dusenbery 1973, 1974) and electrophysiological stimulation of tethered worms (Riga et al. 1995, Perry 1996).

The present results reconcile the seemingly controversial observations of a high selectivity (Tietjen et al. 1970. Tietjen \& Lee 1973, 1977) and a mainly mechanistic and rather unselective food ingestion (Moens \& Vincx 1997) in the feeding of marine nematodes. We suggest that many nematode species select spots where suitable food is abundant from a distance, but may feed rather non-selectively therein. Their response to food is thus highly selective, but their ingestion may be less so.

Chemotaxis is considered an important factor underlying the patchiness of benthic harpacticoid copepods, though passive dispersal through hydrodynamic forces may be of equal importance (Fleeger et al. 1995, and references therein). The nematodes studied here are typical 'Aufwuchs' species, and probably subject to considerable hydrodynamic disturbance, as most of their habitat is inundated at high tide. In a similar habitat, the densities of Diplolaimelloides bruciei were significantly reduced by flooding (Alkemade et al. 1994). The capacity to efficiently find suitable feeding spots may therefore be vital to nematodes living in these dynamic environments. It is as yet unclear at what distances food spots can be recognized and how the nematodes move towards them. Jensen (1981) demonstrated that, next to movement on or through a substrate, some nematodes may show a chemotactically driven swimming behaviour.

Food is clearly not the only factor underlying the patchiness of benthic and Aufwuchs environments. Nematodes have been shown to respond with almost incredible accuracy to temperature gradients (Hedgecock \& Russell 1975, Thomas 1995) and to use temper- ature patterns for their positioning in soils (Dusenbery 1988, 1989, 1996, Robinson 1994). Plant parasites may orientate along redox-induced gradients (Bird 1959) or electric fields (Robertson \& Forrest 1989) around plant roots. They may respond to subtle changes in $\mathrm{pH}$ (Ward 1973), and structural heterogeneity, which is omnipresent in a benthic environment, has recently been shown to interact with chemotaxis to give complex patterns of attraction to bacterial cues (Anderson et al. $1997 \mathrm{a}, \mathrm{b})$. There can be little doubt that taxis is not restricted to nematode-bacteria interactions, but equally mediates the response of nematodes with other feeding strategies. Attraction of nematodes to exudates from yeasts and fungi (Balanovà et al. 1979) and repulsion from slime molds (Kessin et al. 1996) have been demonstrated. The principle illustrated here may therefore generally govern nematode-food interrelations in the benthic environment, and as such deserves further study.

Acknowledgements. The first author performed most of the presently reported work under the auspices of a grant as aspirant with the Fund for Scientific Research-Flanders (FWO). Further financial support was received from the Flemish Ministry of Education via GOA contract 92/98-08 to the University of Gent, from the Belgian Federal Ministry of Science via the Impuls Programme Sea (MS/02/080), and from the University of Gent via BOF 98-03, contract no. 12050398. Johan Vandenberghe and Cindy Snauwaert skillfully assisted with the bacterial culture work. Three anonymous referees gave constructive comments on an earlier draft of the manuscript. Drs Peter Herman, Jarle Tufto and Konjev Desender gave valuable comments concerning different possibilities for the statistical analysis of our data.

\section{LITERATURE CITED}

Alkemade $\mathrm{R}$, Wielemaker A, Herman PM.J, Hemminga MA (1994) Population dynamics of Diplolaimelloides bruciei, a nematode associated with the salt marsh plant Spartina anglica. Mar Ecol Prog Ser 105:277-284.

Anderson ARA, Young IM. Sleeman BD, Griffiths BS, Robertson WM (1997a) Nematode movement along a chemical gradient in a structurally heterogeneous environment. 1 Experiment. Fundam Appl Nematol 20:157-163

Anderson ARA, Sleeman BD, Young IM, Griffiths BS (1997b] Nematode movement along a chemical gradient in a structurally heterogeneous environment. 2. Theory. Fundam Appl Nematol 20:165-172

Andrew PA. Nicholas WL (1976) Effect of bacteria on dispersal of Caenorhabditis elegans (Rhabditidae). Nematologica $22: 451-461$

Balanovà J, Balân J, Krickovà L, Nemec P, Bobok D (1979) Attraction of nematodes to metabolites of yeasts and fungi. J Chem Ecol 5:909-918

Bargmann CI, Hartwieg E, Horvitz HR (1993) Odorant selective genes and neurons mediate olfaction in $C$ elegans. Cell 74:515-527

Bird AF (1959) The attractiveness of roots to the plant parasitic nematodes Meloidogyne javanica and $M$. hapla. Nematologica 4:322-335 
Bouwman LA, Romeyn K, Kremer DR, van Es FB (1984) Occurrence and feeding biology of some nematode species in estuarine aufwuchscommunities. Cah Biol Mar 25: 287-303

Buerkel E (1901) Biologische Studien über die Fauna der Kieler Föhrde. Lipsius \& Tischler, Kiel

Coomans A. De Grisse A (1981) Sensory structures. In: Zuckerman BM, Rohde RA (eds) Plant parasitic nematodes, Vol III. Academic Press, New York, p 127-174

Crisp DJ, Meadows PS (1963) Adsorbed layers: the stimulus to settlement in barnacles. Proc R Soc Lond B 158:364-387

Croll NA (1970a) The behaviour of nematodes: their activity, senses and responses. Edward Arnold, London

Croll NA (1970b) An analysis of swarming in Panagrellus redivivus. Nematologica 16:382-386

Croll NA, Sukhdeo VK (1981) Hierarchies in nematode behavior. In: Zuckerman BM, Rohde RA (eds) Plant parasitic nematodes, Vol III. Academic Press, New York, p 227-251

Dietrich G, Kalle K (1957) Allgemeine Meereskunde. Eine Einführung in die Ozeanographie. Gebrüder Borntraeger, Berlin

Doncaster CC, Webster JM (1968) Clumping of the plant parasitic nematode Ditylenchus dipsaci in water. Nematologica 14:131-136

Dusenbery DB (1973) Countercurrent separation: a new method for studying behavior of small aquatic organisms. Proc Natl Acad Sci USA 70:1349-1352

Dusenbery DB (1974) Analysis of chemotaxis in the nematode Caenorhabditis elegans by countercurrent separation. J Exp Zool 188:41-47

Dusenbery DB (1975) The avoidance of D-tryptophan by the nematode Caenorhabditis elegans. J Exp Zool 193: $413-418$

Dusenbery DB (1976a) Chemotactic behavior of mutants of the nematode Caenorhabditis elegans that are defective in their attraction to sodium chloride. J Exp Zool 198: $342-351$

Dusenbery DB (1976b) Attraction of the nematode Caenorhabditis elegans to pyridine. Comp Biochem Physiol C Comp Pharmacol 53:1-2

Dusenbery DB (1980) Behavior of free-living nematodes. In: Zuckerman BM (ed) Nematodes as biological models. Academic Press, New York, p 127-158

Dusenbery DB (1983) Chemotactic behavior of nematodes. J Nematol 15:168-173

Dusenbery DB (1988) Avoided temperature leads to the surface: computer modeling of slime mold and nematode thermotaxis. Behav Ecol Sociobiol 22:21.9-223

Dusenbery DB (1989) A simple animal can use a complex stimulus pattern to find a location: nematode thermotaxis in soil. Biol Cybern 60:431-438

Dusenbery DB (1992) Simultaneous tracking of animals by image analysis. In: Häder DP (ed) lmage analysis in biology. CRC Press, Boca Raton, FL, p 329-341

Dusenbery DB (1996) Information is where you find it. Biol Bull 191:124-128

Edmunds JE, Mai WF (1967) Effect of Fusarium oxysporum on movement of Pratylenchus penetrans toward alfalfa roots. Phytopathology 57:468-471

Findlay SEG (1981) Small-scale spatial distribution of meiofauna on a mud-and sandflat. Estuar Coast Shelf Sci 12: $471-484$

Findlay SEG (1982) Influence of sampling scale on apparent distribution of meiofauna on a sandflat. Estuaries 5: 322-324

Fleeger JW, Yund PO, Sun B (1995) Active and passive pro- cesses associated with the initial settlement and postsettlement dispersal of suspended meiobenthic copepods. J Mar Res 53:609-645

Gerlach SA (1977) Attraction to decaying organisms as a possible cause for patchy distribution of nematodes in a Bermuda beach. Ophelia 16:151-165

Gray JS (1966a) Factors controlling the localizations of populations of Protodrilus symbioticus Giard. J Anim Ecol 35: $435-442$

Gray JS (1966b) The attractive factor of intertidal sands to Protodrilus symbioticus Giard. J Mar Biol Assoc UK 46: $627-645$

Gray JS (1967a) Substrate selection by the archiannelid Protodrilus rubropharyngeus Jägersten. Helgoländer Wiss Meeresunters 15:253-269

Gray JS (1967b) Substrate selection by the archiannelid Protodrilus hypoleucos Armenante. J Exp Mar Biol Ecol 1: $47-54$

Gray JS (1968) An experimental approach to the ecology of the harpacticid Leptastacus constrictus Lang. J Exp Mar Biol Ecol 2:278-292

Gray JS, Johnson RM (1970) The bacteria of a sandy beach as an ecological factor affecting the interstitial gastrotrich Turbanella hyalina Schultze. J Exp Mar Biol Ecol 4: $119-133$

Grewal PS, Wright DJ (1992) Migration of Caenorhabditis elegans (Nematoda: Rhabditidae) larvae towards bacteria and the nature of the bacterial stimulus. Fundam Appl Nematol 15:159-166

Hedgecock EM, Russell RL (1975) Normal and mutant thermotaxis in the nematode Caenorhabditis elegans. Proc Natl Acad Sci USA 72:4061-4065

Heip C, Vincx M, Vranken G (1985) The ecology of marine nematodes. Oceanogr Mar Biol Annu Rev 23:399-485

Huettel RN (1986) Chemical communicators in nematodes. J Nematol 18:3-8

Jansson HB, Nordbring-Hertz B (1983) The endoparasitic nematophagous fungus Meria coniospora infects nematodes specifically at the chemosensory organs. J Gen Microbiol 130:39-43

Jensen P (1981) Phytochemical sensitivity and swimming behaviour of the free-living marine nematode Chromadorita tenuis. Mar Ecol Prog Ser 4:203-206

Jensen P (1987) Feeding ecology of free-living aquatic nema todes. Mar Ecol Prog Ser 35:187-196

Kessin RH, Gundersen GG, Zaydfudim V, Grimson $M$, Blanton RL (1996) How cellular slime molds evade nematodes. Proc Natl Acad Sci USA 93:4857-4861

Klingler J (1965) On the orientation of plant nematodes and of some other soil animals. Nematologica 11:4-18

Lambshead PJD (1993) Recent developments in marine benthic biodiversity. Oceanis 19:5-24

Lee JJ, Tietjen JH, Mastropaolo C, Rubin H (1977) Food quality and the heterogeneous spatial distribution of meiofauna. Helgoländer Wiss Meeresunters 30:272-282

Lorenzen S, Prein M, Valentin C (1987) Mass aggregations of the free-living marine nematode Pontonema vulgare (Oncholaimidae) in organically polluted fjords. Mar Ecol Prog Ser 37:27-34

Meyers SP, Hopper BE (1966) Attraction of the marine nematode, Metoncholaimus sp., to fungal substrates. Bull Mar Sci 16:142-150

Meyers SP, Hopper BE (1967) Studies on marine fungalnematode associations and plant degradation. Helgoländer Wiss Meeresunters 15:270-281

Moens T, Vincx M (1997) Observations on the feeding ecology of estuarine nematodes. J Mar Biol Assoc UK 77:211-227 